\title{
Qualidade da semeadura de soja em função da velocidade do trator-semeadora e disco dosador de sementes
}

\author{
Quality of soybean sowing as a function of the speed of the sowing tractor and seed metering disk \\ Calidad de la siembra de soja en función de la velocidad del tractor-sembrador y del disco
} dosificador de semillas

Recebido: 05/02/2021 | Revisado: 11/02/2021 | Aceito: 12/02/2021 | Publicado: 19/02/2021

Felipe José Barbosa Franco

ORCID: https://orcid.org/0000-0003-1792-6443 Instituto Federal de Educação, Ciência e Tecnologia Goiano, Brasil E-mail: felipejose85franco@gmail.com

Ariel Muncio Compagnon

ORCID: https://orcid.org/0000-0003-3133-046X Instituto Federal de Educação, Ciência e Tecnologia Goiano, Brasil E-mail: ariel.compagnon@ifgoiano.edu.br

Walter José Pereira Filho

ORCID: https://orcid.org/0000-0001-5335-4716 Instituto Federal de Educação, Ciência e Tecnologia Goiano, Brasil E-mail: pereirafilho123@outlook.com

Mateus Vieira de Jesus

ORCID: https://orcid.org/0000-0001-6287-1758 Instituto Federal de Educação, Ciência e Tecnologia Goiano, Brasil E-mail: mateusvieira-@hotmail.com

Luíla Macêdo Lemes

ORCID: https://orcid.org/0000-0002-1787-9176 Instituto Federal de Educação, Ciência e Tecnologia Goiano, Brasil E-mail: luilamacedolemes.lml@gmail.com

Nilson Dias Rosa Neto

ORCID: https://orcid.org/0000-0002-3924-7946 Instituto Federal de Educação, Ciência e Tecnologia Goiano, Brasil E-mail: nilsonneto33@gmail.com

\begin{abstract}
Resumo
As semeadoras de precisão são submetidas a diversas condições de trabalho, que podem causar variação na distribuição espacial de sementes na linha de semeadura. O objetivo deste trabalho foi avaliar a qualidade da semeadura da cultura da soja em função da velocidade de avanço do trator-semeadora e do disco dosador de sementes, em plantio direto. $\mathrm{O}$ delineamento experimental foi o inteiramente casualizado, com 10 tratamentos em esquema fatorial $5 \times 2$, compostos por cinco velocidades de avanço do trator-semeadora-adubadora $\left(3,4,5,6\right.$ e $\left.7 \mathrm{~km} \mathrm{~h}^{-1}\right)$ e dois discos dosadores de sementes ( 40 e 108 alvéolos), com cinco repetições por tratamento. Foram avaliados o número de dias para emergência, profundidade de semeadura, estande inicial e final, distribuição longitudinal de plantas, altura de plantas e inserção da primeira vagem, produtividade e massa de mil grãos. O incremento da velocidade de semeadura influenciou na redução da porcentagem de espaçamentos aceitáveis, e consequentemente, aumentou a porcentagem de espaçamentos duplos e falhos. Entretanto, as velocidades de deslocamento não influenciaram na produtividade e massa de mil grãos, produzindo média de 5017,46 $\mathrm{kg} \mathrm{ha}^{-1}$ e $168,89 \mathrm{~g}$, respectivamente. O disco com 108 alvéolos apresentou maior porcentagem de espaçamentos aceitáveis e maior massa de mil grãos, porém não influenciando na produtividade de grãos. Nas condições estudadas, é indicado a velocidade de $7 \mathrm{~km} \mathrm{~h}^{-1}$ e o disco de 108 alvéolos, visando uma melhor capacidade de campo operacional.
\end{abstract}

Palavras-chave: Distribuição longitudinal; Glycine max; Produtividade; Semeadora pneumática.

\begin{abstract}
The precision seeders are submitted to different working conditions, which can cause variation in the spatial distribution of seeds in the sowing line. The objective of this work was to evaluate the quality of the sowing of the soybean crop as a function of the advance speed of the tractor-seeder and of the seed dosing disc, in no-tillage. The experimental design was completely randomized, with 10 treatments in a $5 \times 2$ factorial scheme, composed of five forward speeds of the tractor-seeder-fertilizer (3, 4, 5, 6 and $\left.7 \mathrm{~km} \mathrm{~h}^{-1}\right)$ and two seed dosing discs (40 and 108 alveoli), with five repetitions per treatment. The number of days for emergence, sowing depth, initial and final stand, longitudinal distribution of plants, plant height and insertion of the first pod, productivity and mass of a thousand
\end{abstract}


grains were evaluated. The increase in sowing speed influenced the reduction in the percentage of acceptable spacing, and consequently, the percentage of double and flawed spacing increased. However, the displacement speeds did not influence the productivity and mass of a thousand grains, producing an average of $5017.46 \mathrm{~kg} \mathrm{ha}^{-1}$ and $168.89 \mathrm{~g}$, respectively. The disk with 108 wells showed a higher percentage of acceptable spacing and a greater mass of a thousand grains, but did not influence grain yield. In the studied conditions, the speed of $7 \mathrm{~km} \mathrm{~h}^{-1}$ and the disk of 108 alveoli are indicated, aiming at a better operational field capacity.

Keywords: Longitudinal distribution; Glycine max; Productivity; Pneumatic seeder.

\section{Resumen}

Las sembradoras de precisión se someten a diferentes condiciones de trabajo, lo que puede provocar variaciones en la distribución espacial de semillas en la línea de siembra. El objetivo de este trabajo fue evaluar la calidad de la siembra del cultivo de soja en función de la velocidad de avance del tractor-sembrador y del disco dosificador de semilla, en labranza cero. El diseño experimental fue completamente al azar, con 10 tratamientos en un esquema factorial 5x2,

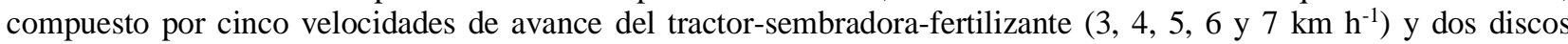
dosificadores de semillas (40 y 108 alvéolos), con cinco repeticiones por tratamiento. Se evaluó el número de días de emergencia, profundidad de siembra, rodal inicial y final, distribución longitudinal de plantas, altura de planta e inserción de la primera vaina, productividad y masa de mil granos. El aumento de la velocidad de siembra influyó en la reducción del porcentaje de espaciamiento aceptable y, en consecuencia, aumentó el porcentaje de espaciamiento doble y defectuoso. Sin embargo, las velocidades de desplazamiento no influyeron en la productividad y masa de mil granos, produciendo un promedio de $5017,46 \mathrm{~kg} \mathrm{ha}^{-1}$ y 168,89 g, respectivamente. El disco con 108 pozos mostró un mayor porcentaje de espaciamiento aceptable y una mayor masa de mil granos, pero no influyó en el rendimiento de grano. En las condiciones estudiadas se indica la velocidad de $7 \mathrm{~km} \mathrm{~h}^{-1}$ y el disco de 108 alvéolos, apuntando a una mejor capacidad de campo operacional.

Palabras clave: Distribución longitudinal; Glycine max; Productividad; Sembradora neumática.

\section{Introdução}

A soja (Glycine max (L.) Merrill) corresponde a 49\% da área semeada com grãos do país, sendo a cultura agrícola que mais cresceu nas últimas três décadas, e o aumento de sua produtividade está associado a avanços tecnológicos, manejo e eficiência dos produtores (Santos et al., 2017). De acordo com dados da Conab (2020), na safra 2019/2020, a soja ocupou 36.949,8 milhões de hectares, onde se alcançou uma produção de 124.844,5 milhões de toneladas, representando um aumento de $4,3 \%$ em relação à safra passada.

O bom desempenho da cultura da soja no campo depende de vários fatores, sendo um deles a qualidade da semeadura. Na operação de semeadura, o estande adequado e a uniformidade de distribuição de sementes são apontados como variáveis de alta influência na produtividade (Reynaldo et al., 2016). A operação de semeadura deve garantir uniformidade na distribuição do adubo e das sementes, proporcionando ao final um estande de plantas adequado (Bottega et al., 2014).

Nas lavouras de soja há variações causadas por má eficiência da semeadora na distribuição de sementes no solo, e consequentemente, o estande de plantas ficam desuniformes, propiciando pontos de acúmulo, gerando plantas mais altas, com menor ramificação e tendência ao tombamento, reduzindo a produtividade (Castela Júnior et al., 2014). O aumento de espaçamentos falhos abre espaços na linha de cultivo, proporcionando o desenvolvimento de plantas competidoras, impossibilitando que os recursos energéticos cheguem totalmente às plantas (Tourino et al., 2002).

Um dos fatores que influencia na operação de semeadura é a velocidade de avanço do trator-semeadora. Quando é mais elevada, influencia no aumento da capacidade operacional; por outro lado, pode comprometer a qualidade da semeadura (Furlani et al., 2010). Segundo Garcia et al. (2011), a velocidade de semeadura é um dos fatores que mais interferem no estabelecimento do estande de plantas e na produtividade da cultura, influenciando também a velocidade dos mecanismos dosadores, e consequentemente, na distribuição longitudinal das sementes no solo.

Destaca-se também o disco dosador de sementes, entendido como um órgão bastante importante na semeadora de precisão, que de acordo com a densidade de semeadura desejada, é responsável por conduzir as sementes do reservatório ao solo (Damasceno, 2017). Os dosadores mais utilizados no controle de dosagem de sementes são os de disco mecânico horizontal e os pneumáticos à vácuo. Segundo Alonço et al. (2014), a melhor distribuição longitudinal das sementes é feita 
pelos pneumáticos, e consequentemente, proporciona maior produtividade de grãos.

Diante o abordado, objetivou-se avaliar a qualidade da semeadura da cultura da soja em função da velocidade de avanço do trator-semeadora-adubadora e do disco dosador de sementes, em plantio direto.

\section{Metodologia}

O trabalho foi realizado em área da Fazenda Bom Sucesso, localizada no município de São Luiz do Norte - GO, no entorno das coordenadas $14^{\circ} 53^{\prime} 37^{\prime \prime} \mathrm{S}$ e 49²1’36" O, no período de novembro de 2019 a março de 2020 . O solo da área experimental apresenta textura média (Tabela 1), sendo cultivado em plantio direto há 11 anos, com sucessão das culturas soja e sorgo.

O delineamento experimental foi o inteiramente casualizado, com 10 tratamentos em esquema fatorial $5 \times 2$, sendo os mesmos compostos por cinco velocidades de avanço do trator-semeadora-adubadora (3, 4, 5, 6 e $\left.7 \mathrm{~km} \mathrm{~h}^{-1}\right)$ e dois discos dosadores de sementes com diferentes números de alvéolos (40 e 108), com cinco repetições por tratamento, totalizando 50 parcelas experimentais, cada uma com $15 \mathrm{~m}$ de comprimento por 4,05 $\mathrm{m}$ de largura, tendo área de 60,75 $\mathrm{m}^{2}$.

Foi utilizada uma semeadora-adubadora marca John Deere modelo 1109, de arrasto, equipada para plantio direto, com sistema dosador de sementes tipo pneumático (sistema Hi Flow), pantográfica, com oito linhas de semeadura espaçadas à 0,50 m, disco de corte de 18 polegadas de diâmetro, disco duplo para deposição do adubo a $15 \mathrm{~cm}$ de profundidade, sendo tracionada por trator da marca Valtra modelo BM 125i, com $125 \mathrm{cv}$ de potência no motor, e tração 4x2 TDA (tração dianteira auxiliar).

Foram utilizadas sementes de soja da variedade Brasmax Desafio RR, já utilizada pela fazenda, com densidade de semeadura de 20 sementes por metro, conforme recomendação agronômica. A cultivar é do grupo de maturação 7.4, possui alta exigência em fertilidade, ideal para ambientes de alta tecnologia.

Foi feita análise textural e química do solo para melhor caracterização da área experimental (Tabela 1). Na adubação de plantio foram aplicados $450 \mathrm{~kg} \mathrm{ha}^{-1}$ da formulação NPK 4-30-10 e $30 \mathrm{~kg} \mathrm{ha}^{-1}$ de Br 12 (Mo 0,01\% + Cu 0,8\% + Mn 2\% + $\mathrm{Zn} 0,7 \%$ ), de acordo com as exigências e necessidade do solo e da cultura, assim como os tratos culturais (aplicação de defensivos) realizados durante o ciclo da cultura.

Tabela 1. Resultado da análise textural e química do solo da área experimental.

\begin{tabular}{|c|c|c|c|c|c|c|c|c|c|c|c|c|c|}
\hline Areia & Silte & Argila & pH & M.O & $\mathbf{C a}$ & Mg & Al & $\mathbf{H}+\mathbf{A l}$ & $\mathbf{K}$ & $\mathbf{T}$ & $\mathbf{P}$ & $\mathbf{V}$ & m \\
\hline \multicolumn{3}{|c|}{---------- $\mathrm{g} \mathrm{kg}^{-1}$-------- } & - & dag $\mathrm{kg}^{-1}$ & $-----\cdot$ & $---\mathrm{cn}$ & $l_{c} d m$ & ---- & & & $\mathrm{mg} \mathrm{dm}{ }^{-3}$ & \multicolumn{2}{|c|}{-- \% -- } \\
\hline 600 & 50 & 350 & 5,2 & 2,5 & 2,8 & 0,9 & 0,0 & 3,40 & 0,3 & 7,4 & 14,5 & 54 & 0 \\
\hline
\end{tabular}

pH em água; $\mathrm{P}$ e K: Extrator Mehlic-1; $\mathrm{Ca}, \mathrm{Mg}$ e $\mathrm{Al}: \mathrm{KCl} 1 \mathrm{~mol} \mathrm{~L}^{-1}$.

Fonte: Laboratório de Solo IF Goiano Campus Ceres (2020).

As variáveis quantitativas analisadas na semeadura foram: profundidade de semeadura: com auxílio de um canivete, no qual se cavou o solo até encontrar a semente, e em seguida com o uso de uma régua graduada, realizou-se a medição do nível do solo até a semente encontrada no sulco; número médio de dias para emergência: com contagens diárias desde a primeira plântula emergida até a estabilização da contagem, calculado de acordo com a metodologia proposta por Edmond e Drapala (1958); distribuição longitudinal de plantas: determinada após a estabilização da emergência, medindo-se com trena a distância entre as plântulas de soja existentes de cada parcela, classificando em espaçamentos aceitáveis (normais), falhos e múltiplos (duplos), conforme metodologia de Kurachi et al. (1989); população inicial de plantas: considerando o número de plântulas estabilizadas nas parcelas; população final de plantas: no mesmo local, contabilizadas no dia da colheita, nos quais os 
valores foram convertidos em plantas por hectare;

$\mathrm{Na}$ colheita, analisou-se as variáveis quantitativas: altura de plantas e de inserção da primeira vagem: determinadas com auxílio de trena graduada e paquímetro, em dez plantas da área útil da parcela, no dia da colheita; número de vagens por planta: em dez plantas de cada parcela durante a colheita; produtividade de grãos de soja: nas plantas contidas nos três metros das duas linhas centrais de cada parcela, que foram colhidas e trilhadas manualmente. Utilizou-se o equipamento Agrologic Portatil Al-101 para medir a umidade dos grãos, sendo posteriormente corrigida para 13\% em base úmida, em seguida transformadas para $\mathrm{kg} \mathrm{ha}^{-1}$, assim como massa de mil grãos; massa de mil grãos: realizada utilizando-se quatro repetições de 200 grãos por tratamento. As sementes de cada repetição foram pesadas e os resultados convertidos para massa de mil grãos. Os dados foram coletados em duas linhas centrais de três metros de cada parcela experimental.

Inicialmente, os dados foram submetidos à análise pela estatística descritiva, no qual foram calculadas as medidas de posição (média, mediana), dispersão (amplitude, desvio padrão e coeficiente de variação), assimetria, curtose e teste de normalidade de Anderson-Darling utilizando o programa R. Posteriormente, os dados experimentais foram submetidos à análise de variância ao nível de 5\% de probabilidade, as médias para as diferentes velocidades de semeadura foram submetidas a análise de regressão e para os tipos de discos dosadores aplicou-se o teste de Tukey ao nível de 5\% de significância, utilizando o programa Sisvar 5.6. As variáveis estande inicial, estande final e produtividade não apresentaram distribuição normal pelo teste normalidade de Anderson Darling, sendo os dados foram transformados pelo programa R, utilizando a transformação Box-Cox.

\section{Resultados e Discussão}

Na Tabela 2 estão os resultados obtidos pela estatística descritiva, no qual possibilitam melhor entendimento de como os dados se comportaram ao longo das avaliações. Exceto as variáveis estande inicial, estande final e produtividade, as demais apresentaram proximidade entre os valores de média e mediana, o que é um indicativo de baixa dispersão dos dados. Os resultados corroboram com Damasceno (2017) avaliando diferentes sistemas dosadores de sementes e velocidades de semeadura direta na cultura da soja.

De acordo com Pimentel-Gomes e Garcia (2002), os valores de coeficiente de variação (CV) podem ser classificados em baixo (menor que 10\%), médio (entre 10 e 20\%), alto (20 a 30\%) e muito alto (quando maior que 30\%). Nesse contexto, as variáveis analisadas apresentaram valores baixos, médios e altos de CV (Tabela 2). Castela Júnior et al. (2014), avaliando o efeito da velocidade de avanço do trator-semeadora na semeadura direta da soja, obtiveram valores entre baixos e médios para essa variável.

Observando os valores de coeficiente de assimetria (Cs) e curtose (Ck), a variável estande final apresentou valores altos para esses parâmetros, indicando alto grau de assimetria dos dados (Tabela 2). É possível visualizar que os demais atributos apresentaram valores de Cs e Ck próximos de zero, dessa forma, mostra que os resultados estão em torno de um valor médio, consequentemente, bem distribuídos. Santos et al. (2011), avaliando a distribuição espacial de sementes de milho na linha de semeadura sob duas velocidades de avanço de uma semeadora-adubadora, observaram baixos valores de Cs e Ck para espaçamentos aceitáveis, falhos e duplos. 
Tabela 2. Parâmetros de estatística descritiva para as variáveis número de dias para emergência (NDE), profundidade de semeadura (PROF), espaçamentos aceitáveis (EA), espaçamentos duplos (ED), espaçamentos falhos (EF), estande inicial (EST. I), estande final (EST. F), altura de plantas (AP), altura de inserção (AI), número de vagem (NV), produtividade (PROD) e massa de mil grãos (MMG) em função da velocidade de semeadura e disco dosador de sementes.

\begin{tabular}{lcccccccc}
\hline \multicolumn{1}{c}{ Variável } & Média & $\mathbf{M e d}^{(\mathbf{1})}$ & $\mathbf{A}^{(\mathbf{2})}$ & $\boldsymbol{\sigma}^{(3)}$ & $\mathbf{C V}^{(\mathbf{4})}$ & $\mathbf{C s}^{(\mathbf{5 )}}$ & $\mathbf{C k}^{(\mathbf{( 6 )}}$ & $\mathbf{A D}^{(\mathbf{7 )}}$ \\
\hline NDE (Dias) & 4,89 & 4,85 & 1,09 & 0,24 & 5,05 & 0,21 & 0,11 & $0,552^{\mathrm{N}}$ \\
PROF (cm) & 4,01 & 4,09 & 3,09 & 0,57 & 14,19 & 0,15 & 0,44 & $0,383^{\mathrm{N}}$ \\
EA (\%) & 54,14 & 54,05 & 25,85 & 6,50 & 12,00 & 0,19 & $-0,72$ & $0,283^{\mathrm{N}}$ \\
ED (\%) & 20,21 & 19,58 & 17,67 & 4,26 & 21,09 & 0,21 & $-0,41$ & $0,264^{\mathrm{N}}$ \\
EF (\%) & 25,64 & 24,86 & 27,11 & 6,25 & 24,38 & 0,68 & 0,26 & $0,738^{\mathrm{N}}$ \\
EST. I (pl ha-1) & 364.733 & 370.000 & 123.333 & 29.875 & 8,19 & $-0,74$ & 0,03 & $0,826^{\mathrm{A}}$ \\
EST. F (pl ha $\left.{ }^{-1}\right)$ & 357.666 & 363.333 & 183.333 & 36.497 & 10,20 & $-1,26$ & 2,36 & $1,396^{\mathrm{A}}$ \\
AP (cm) & 82,05 & 82,25 & 12,10 & 2,97 & 3,62 & $-0,08$ & $-0,88$ & $0,729^{\mathrm{N}}$ \\
AI (cm) & 10,33 & 10,25 & 2,40 & 0,53 & 5,13 & 0,33 & 0,11 & $0,402^{\mathrm{N}}$ \\
NV & 33,62 & 33,45 & 18,30 & 3,84 & 11,44 & 0,87 & 1,27 & $0,542^{\mathrm{N}}$ \\
PROD (kg ha & 5017,46 & 4996,95 & 1217,76 & 260,09 & 5,18 & 0,86 & 0,91 & $1,002^{\mathrm{A}}$ \\
MMG (g) & 168,89 & 168,97 & 14,74 & 2,88 & 1,70 & $-0,03$ & 0,54 & $0,361^{\mathrm{N}}$ \\
\hline
\end{tabular}

${ }^{(1)}$ : mediana; ${ }^{(2)}$ : amplitude; ${ }^{(3)}$ : desvio padrão; ${ }^{(4)}$ : coeficiente de variação $(\%) ;{ }^{(5)}$ : coeficiente de assimetria; ${ }^{(6)}$ : coeficiente de curtose; ${ }^{(7)}$ : valor do teste de normalidade de Anderson-Darling; A: distribuição Assimétrica; ${ }^{\text {N: }}$ distribuição Normal.

Fonte: Autores (2021).

Verificando os valores de coeficiente de curtose ( $\mathrm{Ck}$ ) (Tabela 2), observa-se que as variáveis espaçamento aceitável, espaçamento duplo e altura de planta apresentaram, distribuição platicúrtica, ou seja, pico mais achatado que a curva de distribuição normal. As demais variáveis analisadas apresentaram uma curva de distribuição leptocúrtica, ou seja, mais afunilada que a curva de distribuição normal.

Ainda na Tabela 2, com exceção do estande inicial, estande final e produtividade que apresentaram distribuição assimétrica, os demais atributos apresentaram distribuição normal, mostrando que esses dados podem ser utilizados para análise de variância. Nos estudos de Damasceno (2017), no qual avaliou diferentes sistemas dosadores de sementes e velocidades de semeadura direta na cultura da soja, visualizou que as variáveis profundidade de semeadura e produtividade apresentaram distribuição assimétrica dos dados.

As variáveis número de dias de emergência, profundidade de semeadura, espaçamento aceitável, espaçamento duplo e falho foram influenciadas pelas velocidades (Tabela 3). Já o tipo de disco dosador influenciou no número de dias de emergência, espaçamento aceitável e massa de mil grãos. Não houve interação entre as velocidades de semeadura e disco dosador de sementes.

O estande inicial e final não foram influenciados pelas velocidades de semeadura (Tabela 3), corroborando com Jasper et al. (2011), que não observaram influência da velocidade na semeadora pneumática sobre a população inicial de plantas de soja.

As variáveis altura de plantas, altura de inserção e número de vagens não foram influenciadas pelas velocidades de semeadura (Tabela 3). Os resultados corroboram com Castela Júnior et al. (2014), avaliando o incremento da velocidade de 5,6 a $9,0 \mathrm{~km} \mathrm{~h}^{-1}$.

A produtividade e massa de mil grãos não foram influenciadas pelas velocidades de avanço (Tabela 3), corroborando Moleta et al. (2020), que estudaram a interferência da distribuição mecânica e pneumática de sementes de soja em diferentes velocidades (4, 8 e $12 \mathrm{~km} \mathrm{~h}^{-1}$ ). Por outro lado, Reynaldo et al. (2016), avaliando a influência da velocidade de avanço na semeadura da soja, verificaram que a produtividade reduziu com o aumento da velocidade. 
Tabela 3. Resumo da análise de variância para número de dias para emergência (NDE), profundidade de semeadura (PROF), espaçamentos aceitáveis (EA), espaçamentos duplos (ED), espaçamentos falhos (EF), estande inicial (EST. I), estande final (EST. F), altura de plantas (AP), altura de inserção (AI), número de vagem (NV), produtividade (PROD) e massa de mil grãos (MMG) em função da velocidade de semeadura e disco dosador de sementes.

\begin{tabular}{lcccccc}
\hline \multicolumn{1}{c}{ FV } & NDE & PROF & EA & ED & EF & EST. I \\
\hline Velocidade (V) & $3,945^{*}$ & $3,782^{*}$ & $6,813^{*}$ & $3,813^{*}$ & $3,219^{*}$ & $0,529^{\text {ns }}$ \\
Disco (D) & $8,547^{*}$ & $0,076^{\text {ns }}$ & $8,923^{*}$ & $0,791^{\text {ns }}$ & $4,049^{\text {ns }}$ & $2,343^{\text {ns }}$ \\
Int. V x D & $1,240^{\text {ns }}$ & $0,552^{\text {ns }}$ & $1,389^{\text {ns }}$ & $0,640^{\text {ns }}$ & $0,951^{\text {ns }}$ & $0,646^{\text {ns }}$ \\
\hline CV $(\%)$ & 4,25 & 13,11 & 9,30 & 20,77 & 21,90 & 8,36 \\
\hline \multicolumn{1}{c}{ FV } & EST. F & AP & AI & NV & PROD & MMG \\
\hline Velocidade (V) & $0,903^{\text {ns }}$ & $2,217^{\text {ns }}$ & $1,400^{\text {ns }}$ & $0,465^{\text {ns }}$ & $1,094^{\text {ns }}$ & $3,019^{\text {ns }}$ \\
Disco (D) & $2,628^{\text {ns }}$ & $0,347^{\text {ns }}$ & $1,367^{\text {ns }}$ & $2,039^{\text {ns }}$ & $0,121^{\text {ns }}$ & $5,919^{*}$ \\
Int. V x D & $0,038^{\text {ns }}$ & $0,333^{\text {ns }}$ & $0,721^{\text {ns }}$ & $0,245^{\text {ns }}$ & $0,489^{\text {ns }}$ & $0,901^{\text {ns }}$ \\
\hline CV $(\%)$ & 10,49 & 3,72 & 5,09 & 11,96 & 5,26 & 1,49 \\
\hline
\end{tabular}

FV - Fonte de variação; * significativo a 5\% de probabilidade; ${ }^{\text {ns }}$ Não significativo; CV - Coeficiente de variação.

Fonte: Autores(2021).

Onde Apresentou comportamento quadrático em função das velocidades de semeadura (Figura 1). A semeadura quando foi submetida a velocidade de $3 \mathrm{~km} \mathrm{~h}^{-1}$, as sementes apresentaram um número médio de 4,83 dias para emergirem e as que foram semeadas a $6 \mathrm{~km} \mathrm{~h}^{-1}$ foi possível observar um valor próximo, que foi de 5,06 dias.

Estudando o efeito da velocidade de semeadura no estabelecimento inicial da cultura do feijão, Rinaldi et al. (2010) verificaram que o NDE não é influenciado pela velocidade de avanço do trator-semeadora. Já Trogello et al. (2013), observaram que a menor velocidade de semeadura apresentou o melhor índice de emergência quando testaram diferentes manejos de palhada, mecanismos sulcadores e velocidades de operação em semeadura direta de milho em um solo caracterizado como Latossolo Vermelho distroférrico, com textura muito argilosa na região sudoeste do estado do Paraná.

Figura 1. Número de dias de emergência para soja semeada em diferentes velocidades de avanço do trator-semeadora.

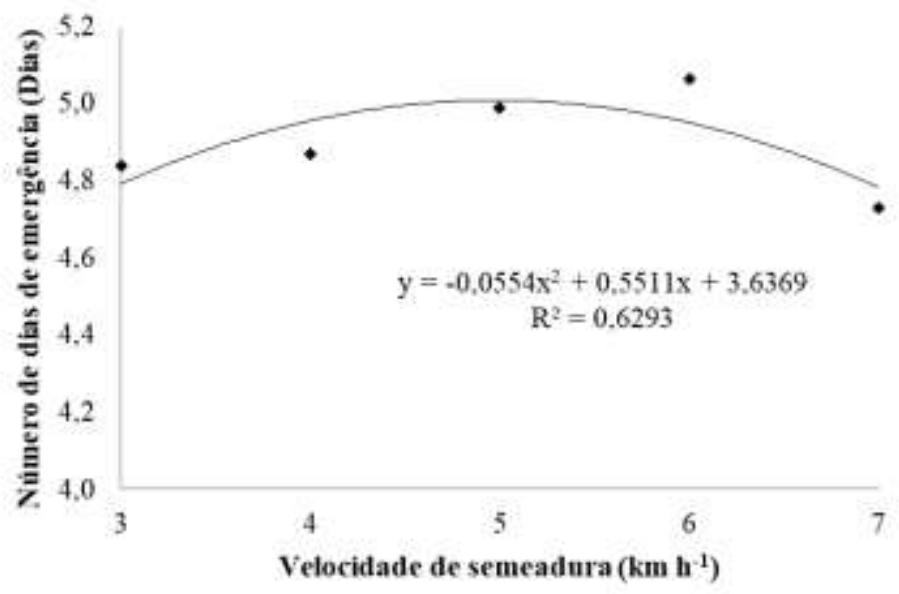

Fonte: Autores (2021).

Para variável profundidade de semeadura (Figura 2), as velocidades de deslocamento apresentaram comportamento quadrático, na qual a menor profundidade foi encontrada para $5 \mathrm{~km} \mathrm{~h}^{-1}$. Houve uma variação entre 3,49 e 4,29 $\mathrm{cm}$ de 
profundidade das sementes, porém todos estes valores estão dentro dos parâmetros ideais. De acordo com Garcia et al. (2007), as sementes de soja devem ser semeadas a uma profundidade de 3 a $5 \mathrm{~cm}$, pois semeaduras em profundidades maiores dificultam a emergência, principalmente em solos arenosos, sujeitos a assoreamento, ou onde ocorre compactação superficial do solo.

Figura 2. Profundidade de sementes de soja semeadas em diferentes velocidades de avanço do trator-semeadora.

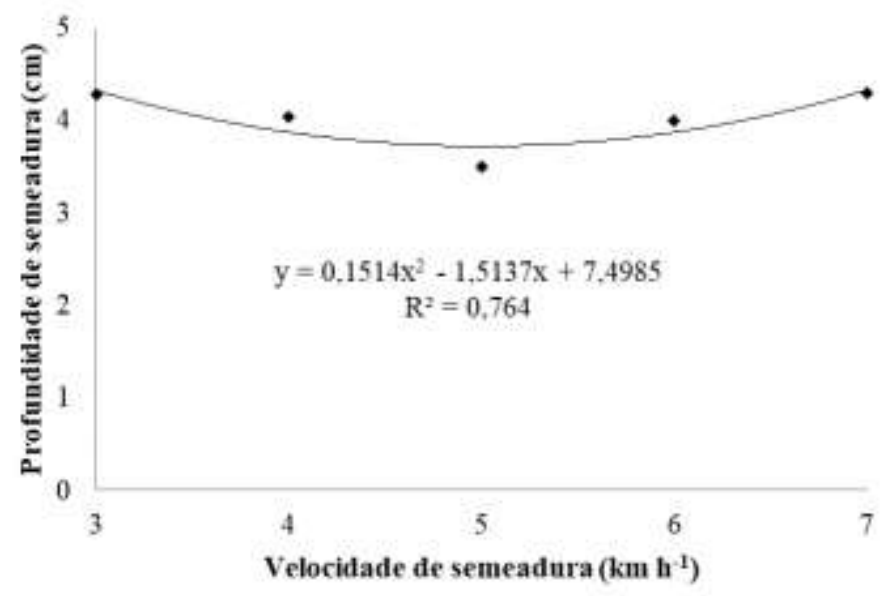

Fonte: Autores (2021).

Na Figura 3, é possível observar que todas as velocidades avaliadas apresentaram valores abaixo do percentual ideal para espaçamento aceitável, que segundo Coelho (1996), devem estar acima de 60\%. Os resultados corroboram com Alonço et al. (2014), avaliando a influência da inclinação transversal sobre o desempenho de três dosadores pneumáticos submetidos a diferentes velocidades de operação utilizando-se sementes de soja.

Figura 3. Porcentagens de espaçamentos aceitáveis, duplos e falhos para soja semeada em diferentes velocidades de avanço do trator-semeadora.

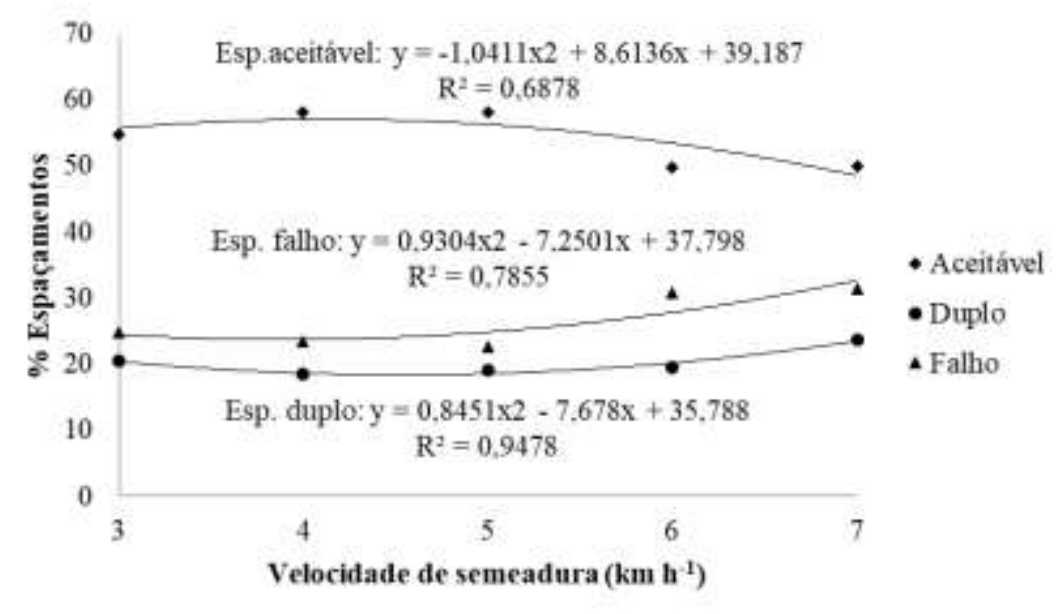

Fonte: Autores (2021).

A partir da análise regressão, o modelo quadrático foi o que melhor se adequou a tendência de respostas da soja em função das velocidades de semeadura para a variável espaçamento aceitável (Figura 3). A porcentagem foi de 54,77; 58,10; 58,$14 ; 49,70$ e $49,98 \%$ para as velocidades de $3,4,5,6$ e $7 \mathrm{~km} \mathrm{~h}^{-1}$, respectivamente. 
Tiesen et al. (2014), estudando a influência da velocidade de semeadura no cultivo de soja, observaram aumento dos espaçamentos aceitáveis entre plântulas quando se diminuiu a velocidade de avanço trator-semeadora de 7 para $3 \mathrm{~km} \mathrm{~h}^{-1}$. Por outro lado, Furlani et al. (2010) avaliando o manejo da cobertura vegetal do milheto e diferentes velocidades de avanço do conjunto mecanizado na cultura da soja, concluíram que a velocidade de semeadura não afeta os espaçamentos aceitáveis.

A porcentagem de espaçamentos falhos apresentou tendência de crescimento quadrático (Figura 3), sendo que para a velocidade de $3 \mathrm{~km} \mathrm{~h}^{-1}$ obteve 24,85\% e para velocidade de $7 \mathrm{~km} \mathrm{~h}^{-1}$ apresentou crescimento de 31,06\%. Para variável espaçamentos duplos, o modelo quadrático foi o que também melhor se ajustou à tendência de resposta da soja em função das diferentes velocidades, apresentando 20,36 e 23,65\% para as velocidades 3 e $7 \mathrm{~km} \mathrm{~h}^{-1}$, respectivamente.

A velocidade de avanço trator-semeadora é um dos fatores mais importantes na semeadura, pois ela determina a distribuição espacial das sementes na linha (Fantin et al., 2016). Reynaldo et al. (2016) concluíram que o aumento na velocidade de avanço da semeadora interferiu nos espaçamentos falhos e duplos. Jasper et al. (2011), ao estudar a influência da velocidade de semeadura nos espaçamentos múltiplos, verificaram que a distribuição das sementes pelo sistema de disco alveolado horizontal não foi afetada.

Analisando a Tabela 4, observa-se diferença na variável número de dias para emergência para o tratamento disco dosador, no qual o de 40 alvéolos apresentou maior $\operatorname{NDE}$ (4,98 dias), enquanto o com 108 alvéolos apresentou menor de valor (4,81 dias). Para profundidade de semeadura, não houve diferença entre os tratamentos. Bottega et al. (2018), avaliando desempenho de duas semeadoras-adubadoras equipadas com diferentes mecanismos dosadores de sementes em três velocidades de semeadura na implantação de uma lavoura de milho em sistema de plantio direto, concluíram que valor médio de velocidade emergência para o dosador pneumático foi maior e diferiu do valor observado para o dosador tipo disco horizontal perfurado.

Tabela 4. Teste de médias para número de dias para emergência (NDE), profundidade de semeadura (PROF), espaçamento aceitável (EA), espaçamento duplo (ED), espaçamento falho (EF), estande inicial (EST. I), estande final (EST. F), altura de plantas (AP), altura de inserção (AI), número de vagem (NV), produtividade (PROD) e massa de mil grãos (MMG) em função dos diferentes discos.

\begin{tabular}{|c|c|c|c|c|c|c|}
\hline Disco & $\begin{array}{l}\text { NDE } \\
\text { (Dias) }\end{array}$ & $\begin{array}{c}\text { PROF } \\
(\mathrm{cm})\end{array}$ & $\begin{array}{l}\text { EA } \\
(\%)\end{array}$ & $\begin{array}{l}\text { ED } \\
(\%)\end{array}$ & $\begin{array}{l}\mathrm{EF} \\
(\%)\end{array}$ & $\begin{array}{c}\text { EST. I } \\
\left(\mathrm{pl} \mathrm{ha}^{-1}\right)\end{array}$ \\
\hline 40 alvéolos & $4,98 \mathrm{a}$ & 3,99 & $52,01 \mathrm{~b}$ & 20,74 & 27,23 & 358133,33 \\
\hline 108 alvéolos & $4,81 \mathrm{~b}$ & 4,03 & 56,27 a & 19,68 & 24,04 & 371333,33 \\
\hline Disco & $\begin{array}{l}\text { EST. F } \\
\left(\text { pl ha }^{-1}\right)\end{array}$ & $\begin{array}{l}\text { AP } \\
(\mathrm{cm})\end{array}$ & $\begin{array}{c}\text { AI } \\
(\mathbf{c m})\end{array}$ & NV & $\begin{array}{c}\text { PROD } \\
\left(\mathrm{kg} \mathrm{ha}^{-1}\right)\end{array}$ & $\begin{array}{c}\text { MMG } \\
\text { (g) }\end{array}$ \\
\hline 40 alvéolos & 349066,66 & 81,79 & 10,24 & 32,81 & 5028,08 & $167,92 \mathrm{~b}$ \\
\hline 108 alvéolos & 366266,66 & 82,30 & 10,42 & 34,44 & 5006,83 & 169,85 a \\
\hline
\end{tabular}

Médias seguidas por letras distintas na coluna diferem entre si pelo teste de Tukey a 5\% de probabilidade.

Fonte: Autores (2021).

Para espaçamento aceitável, o disco com 108 alvéolos apresentou maior valor de porcentagem (Tabela 4). A maior quantidade de alvéolos proporcionou melhor distribuição longitudinal das plantas, fazendo com que o disco tenha velocidade periférica menor quando comparado ao disco com 40 alvéolos, uma vez que gira quase três vezes mais rápido, diminuindo a percentagem de espaçamentos aceitáveis. Para espaçamentos duplos e falhos não houve diferenças.

Dias et al. (2014) avaliando o efeito da velocidade periférica do disco dosador de sementes em mecanismos dosadores 
pneumáticos e de disco alveolado horizontal, com as culturas do milho e soja, em ensaio de laboratório, concluíram que o percentual de espaçamentos aceitáveis reduziu de maneira linear com o aumento da velocidade periférica do disco para ambas as culturas. Já Bottega et al. (2014), comparando o desempenho de sistemas dosadores de sementes e velocidades de semeadura na implantação da cultura do milho, observaram que o aumento da velocidade de deslocamento provocou aumento na incidência de espaçamentos falhos e duplos, independente do dosador de sementes utilizado.

Para estande inicial e final não houve diferença entre os discos (Tabela 4). Isso pode ser devido a semeadoraadubadora ser pneumática de precisão, sendo assim, pode-se trabalhar com ambos os discos. Pinheiro Neto et al. (2008), avaliando o desempenho de mecanismos dosadores de sementes em diferentes velocidades e condições de cobertura do solo, observaram a redução da população de plantas, que de acordo com a recomendação agronômica, não foi alcançada por ambos mecanismos dosadores.

Não houve diferença entre os tratamentos para as variáveis altura de plantas, altura de inserção da primeira vagem, número de vagens e produtividade (Tabela 4). Entretanto, o disco de 108 alvéolos apresentou maior valor para o parâmetro massa de mil grãos. Jasper et al. (2011) não encontraram diferenças para o componente produtividade de soja para semeadoras mecânicas e pneumáticas com o incremento da velocidade de 4 a $12 \mathrm{~km} \mathrm{~h}^{-1}$.

\section{Conclusão}

O incremento da velocidade de semeadura influenciou na redução da porcentagem de espaçamentos aceitáveis, e consequentemente, aumentou a porcentagem de espaçamentos duplos e falhos. Entretanto, as velocidades de avanço não influenciaram na produtividade e massa de mil grãos, produzindo média de 5017,46 kg ha ${ }^{-1}$ e 168,89 g, respectivamente.

O disco com 108 alvéolos apresentou maior porcentagem de espaçamentos aceitáveis e maior massa de mil grãos, porém não influenciando na produtividade de grãos.

Nas condições estudadas, é indicado a velocidade de $7 \mathrm{~km} \mathrm{~h}^{-1}$ e o disco de 108 alvéolos, visando uma melhor capacidade de campo operacional.

Sugere-se, para trabalhos futuros, testes com velocidades mais altas de semeadura e discos com outras quantidades de alvéolos, bem como estudos em semeadoras com dosadores mecânicos.

\section{Agradecimentos}

Ao Instituto Federal Goiano - Campus Ceres pelo apoio na execução do projeto. E aos Srs. Moacir, Reginaldo e Rayan Naves por cederem a área e máquinas de sua propriedade para a execução do experimento.

\section{Referências}

Alonço, A. S., Silveira, H. A. T., Bellé, M. P., Carpes, D. P., \& Machado, O. D. C. (2014). Influência de inclinação transversal e velocidade de operação sobre o desempenho de dosadores pneumáticos com sementes de soja. Engenharia na agricultura, 22(2), 119-27.

Bottega, E. L., Braido, R., Piazetta, H. V., Oliveira Neto, A. M., \& Guerra, N. (2014). Efeitos da profundidade e velocidade de semeadura na implantação da cultura do milho. Pesquisa Agropecuária de Pernambuco, 19(2), 74-8.

Castela Junior, M. A., Oliveira, T. C., Figueiredo, Z. N., Samogim, E. M., \& Caldeira, D. S. A. (2014). Influência da velocidade da semeadora na semeadura direta da soja. Enciclopédia Biosfera, 10(19), 1199-1207.

Coelho, J. L. D. (1996). Ensaio \& certificação das máquinas para semeadura. In: Mialhe, L. G (Ed). Máquinas agrícolas: ensaio e certificação: Fundação de Estudos Agrários Luiz de Queiroz

Companhia Nacional do Abastecimento. (2020). Acompanhamento da safra brasileira de grãos, 2020: Conab.

Damasceno, A. F. (2017). Sistema dosador de sementes e velocidade de operação na semeadura direta de soja (Dissertação de Mestrado. Universidade Estadual Paulista, Jaboticabal, São Paulo. 
Dias, V. O., Alonço, A. S., Carpes, D. P., Veit, A. A., \& Souza, L. B. (2014). Velocidade periférica do disco em mecanismos dosadores de sementes de milho e soja. Ciência Rural, 44(11), 1973-1979.

Edmond, J. B., \& Drapala, W. L. (1958). The effects of temperature, sand and soil acetone on germination of okra seed. Proceedings of the American Society for Horticultural Science, 71, 428-434.

Fantin, N. A. M., Meert, L., Hanel, A., Alencar, J. R. C. C., \& Petean, L. P. (2016). Componentes de produção e qualidade de semeadura de soja em função de diferentes velocidades do conjunto trator+semeadora. Brazilian Journal of Applied Technology for Agricultural Science, 9(3), 7-15.

Furlani, C. E. A., Pavan Júnior, A., Cortez, J. W., Silva, R. P., \& Grota, D. C. C. (2010). Influência do manejo da cobertura vegetal e da velocidade de semeadura no estabelecimento da soja (Glycine max). Engenharia na Agricultura, 18(3), 227-233.

Garcia, A., Pípolo, A. E., Lopes, I. A. N., \& Portugal, F. A. F. (2007). Instalação da lavoura de soja: Época, Cultivares, Espaçamento e População de Plantas: Embrapa Soja.

Garcia, R. F., Vale, W. G., Oliveira, M. T. R., Pereira, E. M., Amim, R. T., \& Braga, T. C. (2011). Influência da velocidade de deslocamento no desempenho de uma semeadora-adubadora de precisão no Norte Fluminense. Acta Scientiarum Agronomy, 33, 417-422.

Jasper, R., Jasper, M., Assumpção, P. S. M., Rocil, J., \& Garcia, L. C. (2011). Velocidade de semeadura da soja. Engenharia Agrícola, 31(1), 102-110.

Kurachi, S. A. H., Costa, J. A. S., Bernardi, J. A., Coelho, J. L. O., \& Silveira, G. M. (1989). Avaliação tecnológica de semeadoras e/ou adubadoras: tratamento de dados de ensaios e regularidade de distribuição longitudinal de sementes. Bragantia, 48(2), $249-262$.

Moleta, I., Rampim, L., Conrado, P. M., Czekalski, A. M., Pott, C. A., Faria, V. de O., Spliethoff, J., Brito, T. S., Martins, L., de O. \& Wendler, C. D. (2020). Desempenho de semeadora-fertilizante pneumática e mecânica em diferentes velocidades na cultura da soja. Pesquisa, Sociedade e Desenvolvimento, 9(10), 119.

Pimentel-Gomes, F., \& Garcia. C. H. (2002). Estatística aplicada a experimentos agronômicos e florestais: exposição com exemplos e orientações para uso de aplicativos: FEALQ.

Pinheiro Neto, R., Braccini, A. L., Scapim, C. A., Bortolotto, V. C., \& Pinheiro, A. C. (2008). Desempenho de mecanismos dosadores de sementes em diferentes velocidades e condições de cobertura do solo. Acta Scientiarium Agronomy, 30, 611-617.

Reynaldo, E. F., Machado, T. M., Taubinger, L., \& Quadros, D. (2016). Influência da velocidade de deslocamento na distribuição de sementes e produtividade de soja. Engenharia na Agricultura, 24(1), 63-67.

Rinaldi, P. C. N., Fernandes, H. C., Teixeira, M. M., Silveira, J. C. M., \& Magno Júnior, R. G. (2010). Influência da profundidade de adubação e da velocidade de uma semeadora no estabelecimento inicial da cultura do feijão (Phaseolus vulgaris, L.). Engenharia na Agricultura, 18(2), 123-130.

Santos, T. D., Meert, L., Borghi, W. A., Silva, P. S., \& Figueiredo, A. S. T. (2017). Desenvolvimento inicial de plantas de soja e qualidade de semeadura em função da velocidade de deslocamento da semeadora e textura do solo. Brazilian Journal of Applied Technology for Agricultural Science, 10(2), 97-103.

Tiesen, C. M. A., Vale, W. G., Silva, A. F., Shiratsuchi, L. S., Silva, C., \& Rimoli, M. F. S. (2016). Influência da velocidade de semeadura no cultivo de soja. Scientific Electronic Archives, 9(5), 1-10.

Tourino, M. C. C., Rezende, P. M., \& Salvador, N. (2002). Espaçamento, densidade e uniformidade de semeadura na produtividade e características agronômicas da soja. Pesquisa Agropecuária Brasileira, 37(8), 1071-1077.

Trogello, E., Modolo, A. J., Scarsi, M., \& Dallacort, R. (2013). Manejos de cobertura, mecanismos sulcadores e velocidades de operação sobre semeadura direta da cultura do milho. Bragantia, 72(1), 101-109. 